\title{
Effect of training brief self-regulation couple therapy on marital satisfaction of incompatible couples \\ Mohsen Golparvar ${ }^{1}$, Mohammad Nilbarghi ${ }^{1}$, Mohammad Reza Mosahebi $^{1}$
}

\author{
Journal of Research \& Health \\ Social Development \& Health Promotion \\ Research Center \\ Vol. 6, No. 5, Nov \& Dec 2016 \\ Pages: 495- 503 \\ DOI: 10.18869/acadpub.jrh.6.5.495 \\ Original Article
}

1. Department of Psychology, Faculty of Psychology \& Educational Sciences, Islamic Azad University, Esfahan (Khorasgan) Branch, Esfahan, Iran

Correspondence to: Mohsen Golparvar, Department of Psychology, Faculty of Psychology \& Educational Sciences, Islamic Azad University, Esfahan (Khorasgan) Branch, Esfahan, Iran Email: drmgolparvar@gmail.com

Received: 28 Nay 2013

Accepted: 23 Feb 2014

How to cite this article: Golparvar M, Nilbarghi M, Mosahebi MR. Effect of training brief self-regulation couple therapy on marital satisfaction of incompatible couples. $J$ Research \& Health2016; 6(5): 495- 503.

\begin{abstract}
Couple therapy is among the therapeutic methods used for solving couples' marital problems. Brief self-regulation couple therapy is one of the many different methods used for couple therapy. This study was conducted to determine the effect of training brief selfregulation couple therapy on couples' marital satisfaction. The research method was two-group quasi-experimental with pretest and posttest on a statistical population of incompatible couples presenting to a psychological consultation center. Among the mentioned statistical population, 40 couples ( 80 participant) were selected using convenience sampling method and categorized into experimental and control groups (20 couples each) using simple random method. Training brief couple therapy was presented to the couples of experimental group in eight sessions. Measurement instrument was the short-form marital satisfaction questionnaire. Results showed that training brief self-regulation couple therapy was effective in the components of marital satisfaction (general marital satisfaction, personality issues, marital relations, conflict resolution, financial management, leisure, sexual relations, children and parenting, relatives and friends, and religious orientation) among the incompatible couples. Results of the present work supported the effect of training brief self-regulation couple therapy for strengthening marital satisfaction among incompatible couples.
\end{abstract}

Keywords: Couple Therapy, Incompatibility, Self-Regulation

\section{Introduction}

Couples seek consultation for different reasons such as communication problems, lack of coordination in playing their parenting roles, and emergence of emotions [1,2]. Among different variables in marital relations, marital satisfaction is one of the deepest and most fundamental human experiences [3-5].
Satisfaction of couples with their relations increases longevity, physical and mental health, economic progress, and satisfaction with the whole life $[6,7]$. This phenomenon is mostly generated via mutual interest, caring for each other, mutual acceptance and understanding, and fulfillment of needs 
[8,9]. Self-regulation is one of the methods with acceptable evidence for increasing marital satisfaction [7,8]. Self-Regulation couple therapy (SRCT) refers to the application of selfregulation theory for communication problems. This therapeutic method requires regulation in thoughts, feelings, and behaviors. Skills of self-regulation in marital relations enable couples to change their behavioral, cognitive, and emotional problems and thus gain more capability $[9,10]$.

Couples can be trained for controlling, adjusting and regulating their behavior through counselling in different activities and situations [6,7,11]. Four high-level skills with pivotal importance in self-regulation include selfassessment, self-oriented goal setting, and change implementation, and evaluating changeoriented efforts [12-14]. Self-assessment means that couples can identify the present function of their relation and the factors affecting it and then protect and promote the relation. Self-oriented goal setting means that individual takes active steps for changing adaptive communication processes and assess rate of changes that lead to desirable communication. The third skill, change implementation, includes steps taken by each spouse for changing adaptive processes in future [15]. Finally, evaluating changeoriented efforts is the process with which each spouse assesses the range of fulfillment of desirable behavioral changes and the effect of these changes on the relation. In SRCT, main assessment methods include individual and joint interviews, behavioral self-report scales, and self-monitoring forms which are sometimes used as complementary assessment method. One of the applications of SRCT is a combination of assessment and targeting, which is sufficient for improving communication in some couples [8-11]. Different studies have investigated the effect of SRCT on the dimensions of marital relations $[8,9,15]$.

Some studies have shown that training brief self-regulation strengthens relations, commitment, and satisfaction with relation in couples (both compatible and incompatible) $[7,8]$. It is necessary to note that acquiring skills of commitment and responsibility in relations is the main factors for promoting marital satisfaction $[9,15]$. Research findings relating to the role and effect of training brief self-regulation on marital satisfaction, demonstrated that inability to use selfregulation skills causes violent behaviors between couples [12-14]. Some studies have mentioned that the marital satisfaction of couples can be predicted by training brief selfregulation to men, but presenting the training only for women cannot predict increased satisfaction among them [9]. Nevertheless, more evidence shows that training SRCT for both couples provides more desirable increase in marital satisfaction $[6,15]$. Evidence has also shown that training SRCT is highly stable and does not greatly change over time [6]. The scientific reason is that, when couples use selfregulation skills in their relations, they receive immediate feedbacks in relations which stabilize these skills [6]. Results of a metaanalysis on 117 studies showed that mean effect size of training for the improvement of marital relations fluctuated between 0.3 and 0.36 . This meta-analysis demonstrated that trainings like SRCT can improve the quality of their relations [4]. One of the most important mechanisms for the effectiveness of brief SRCT is that couples are given the skill and ability to focus on the positive aspects of relations and living with each other [15], instead of concentrating on negative relations and emotions with each other, which is common among the couples that apply for divorce [14].

Review of the literature on the efficacy of brief self-regulation on marital satisfaction reveals that there is still a gap in terms of the diversity of the study samples [4]. A look at the studies shows that there are few studies on the efficacy of SRCT among different samples from different countries [12-14]. Furthermore, it is necessary to repeat the studies with samples from different cultures and nations in order to determine the efficacy of a set of educational techniques such as self-regulation $[4,6]$. In this regard, one of the most important necessities for conducting the present research 
was providing scientific knowledge about efficacy of brief self-regulation on marital satisfaction in the Iranian society in order to assist the combination and integration of the results of studies through future meta-analysis works. Therefore, this study aimed to study and determine the effect of brief SRCT on increased marital satisfaction of incompatible couples. Main hypothesis of this study was as follows:

Research hypothesis: Brief SRCT is effective in increased marital satisfaction (general marital satisfaction, personality issues, marital relations, conflict resolution, financial management, leisure, sexual relations, children and parenting, relation with relatives, and religious orientation) among incompatible couples.

\section{Method}

This quasi-experimental research used twogroup design (an experimental group and a control group) with pretest and posttest. The independent variable of this research was training brief SRCT (during eight 60-min sessions) and dependent variable was marital satisfaction (general marital satisfaction, personality issues, marital relations, conflict resolution, financial management, leisure, sexual relations, children and parenting, relation with relatives, and religious orientation). Training brief SRCT was executed based on eight 60-min sessions considering training instructions provided for this type of training in Iran [15]. Statistical population of this research consisted of all couples (wife and husband together) presenting to Harandi Psychological Consultation Center in Isfahan, Iran, in fall 2012 to receive assistance for their problems in marital relations. It is necessary to note that each couple was interviewed at the time of the admission by a psychologist holding an M.A. degree and based on the reasons for going to the center and a psychologist who supervised the results of the interview) to ensure that the couples' communication and marital problems were common and they could participate in the research. After gaining the required assurance, the couples with common communication and marital problems (such as problems in verbal and emotional exchange, relations with others, sexual relations, etc.) were enrolled. In the next stage, marital satisfaction questionnaire was presented as the pretest and scores of the couples who were common in marital satisfaction components were investigated. Then, the participants were entered into the main training stage. Due to the fluidity of referrals during the study, sample size was 75 couples considering the mean visit of 25 couples per month. Based on the recommendations in the literature regarding sample size for experimental questions, 40 couples (40 husbands and 40 wives) were selected using convenience sampling [16]. Because the couples in this research came to the center for their marital problems and accessibility and satisfaction with participation in the project to the end are generally among the main factors affecting quasi-experimental studies such as the present one, couples were initially selected for participation based on satisfaction and consent to participation using convenience method. Moreover, due to disagreement of all couples for participation in the training course, it was not possible to use all the couples as sample for the present research. After convenience sampling, 40 couples (40 husbands and 40 wives) of the research sample were assigned to control and experimental groups (20 couples per group; 20 husbands and 20 wives). Training brief self-regulation in this research was done individually (for each wife and husband together without the participation of other couples). Inclusion criteria were couples' consent (both wife and husband) to participation in the sessions to the end of training, having minimum literacy, no mental disability, no symptoms of severe psychological disorders, and no addiction. It is noteworthy that after completion of the research and in order to observe research ethics, the members of the control group were asked to enroll in the training course of SRCT. To measure marital satisfaction, Olson marital satisfaction questionnaire was used. This questionnaire was first normalized by Soleimanian [17] in 1994 in Tehran as a short 
form. Original version of this questionnaire contains 115 items. Given the evaluation of the items which leads to the excessive fatigue of respondents, a short form of this questionnaire containing 47 items was prepared by Soleimanian [17] in Iran. This paper-and-pencil test takes 10 to $15 \mathrm{~min}$. The 47 -item form includes the subscales of personality issues, marital relations, conflict resolution, financial management, leisure time, sexual relations, children and parenting, relatives and friends, and religious orientation [17]. Responses were scored as five-point Likert scale (Strongly disagree $=1$ to strongly agree $=5$ ). All the subscales of marital satisfaction questionnaire could distinguish between satisfied and dissatisfied couples, which shows that this questionnaire has good discriminative validity [18]. Correlation coefficient of marital satisfaction questionnaire has been reported between 0.41 and 0.6 with scales of family satisfaction and between 0.32 and 0.41 with life satisfaction scales $[17,18]$. Olson [17] reported reliability coefficient of this questionnaire using Cronbach's alpha as 0.92 . In the present research, Cronbach's alpha was calculated for each of the subscales and it was specified that ideal distortion and equalitarian roles had weak Cronbach's alpha. Thus, these two subscales were excluded from the final analyses. Cronbach's alpha of 0.77 , $0.82,0.78,0.82,0.74,0.9,0,81,0.77$, and 0.84 were obtained for the remaining subscales of personality issues, marital relations, conflict resolution, financial management, leisure time, sexual relation, children and parenting, relation with relatives, and religious orientation, respectively. Also, 0.89 was obtained for the entire questionnaire.

BriefSRCT was trained individually for eight 60 min sessions (except for the first session which took $90 \mathrm{~min}$ ) once per week as follows $[1,11]$. The first session: filling out the questionnaire and individual and joint interviews, preparing a list of important strengths and problems of the relation, and preparing a list of factors with an important and effective role in the growth and maintenance of problematic causes of marital relations. The second session: investigating compatible communication processes of couples and studying external pressures, individual problems, and their effect on the couple's relation. In this session, the couples identified compatible processes of their relations and weaknesses which disrupted their relations with the help of the therapist (the researcher). The third session: redefining elements of a positive relation between couples and identifying critical points of marital relations to attributional change so that the couples would become aware of their loneliness and concerns, redefining the elements along with training general elements of communication including verbal skills and comprehension skills, and training comprehension skills i.e. good and proper listening and non-verbal attention to the surrounding; the fourth session: couples' expectations from each other, feedback, and sum of strengths and weaknesses of the marital relations. In this session, the couples considered their expectations from each other about different issues which existed in their life and might have disrupted their relations and identified and studied strengths and weaknesses of their relations. The fifth session: discussion of the couples with the guidance of the therapist (researcher) about the applied relation pattern. The sixth session: determining goals of communication using the applied relation pattern. When each of the couples agreed on the applied pattern, goals of their relation were determined. The seventh session: evaluating training process and motivating them for accurate and regular practice of self-regulation. In order to understand the progress of the couple therapy sessions, the performed stages and trainings were evaluated. The eighth session: reporting of the couples about changes in their relations and posttest. In the last session, the couples reported positive changes in their relations after seven training sessions and then posttest was taken. The data analyzed using tests for investigating pre-assumptions (KolmogorovSmirnov test and Levene's test) and ANCONA (marital satisfaction pretest as covariate and 
marital satisfaction posttest as dependent variable). All of the analyses were performed using SPSS software, ver. 18. It is noteworthy that Chi-square test showed no significant difference between the couples in the control and experimental groups in terms of education and years of married like (up to 5 years and more than 5 years).

\section{Resultes}

Sample size included 80 participants (40 couples). Mean and standard deviation of their age were
34.15 and 8.45 years, respectively. Age range of the participants was between 22 and 50 years (age range of the women was between 22 and 45 and that of men was between 28 and 50 years). Education of the couples participating in this research ranged from high school diploma (48\%) to associate diploma and bachelor's degree (52\%). One of the pre-assumptions of ANCONA is normality of data distribution and another is equality of variances (Levene's test), which are given in Tables 1 and 2.

Table 1 Results of kolmogorov-smirnov test

\begin{tabular}{|c|c|c|c|c|c|c|}
\hline \multirow{2}{*}{ Row } & \multirow{2}{*}{$\begin{array}{l}\text { Marital satisfaction } \\
\text { dimensions }\end{array}$} & \multirow{2}{*}{ Test } & \multicolumn{2}{|c|}{$\begin{array}{l}\text { Experimental } \\
\text { group }\end{array}$} & \multicolumn{2}{|c|}{ Control group } \\
\hline & & & Z & $\mathrm{p}$ & Z & $\mathrm{p}$ \\
\hline 1 & Personality issues & \multirow{10}{*}{$\begin{array}{l}\vec{D} \\
\overrightarrow{0} \\
\vec{i} \\
\vec{D}\end{array}$} & 0.81 & 0.53 & 0.65 & 0.78 \\
\hline 2 & Communication & & 0.64 & 0.8 & 0.78 & 0.57 \\
\hline 3 & Conflict resolution & & 0.98 & 0.29 & 0.73 & 0.67 \\
\hline 4 & Financial management & & 0.89 & 0.4 & 0.67 & 0.76 \\
\hline 5 & Leisure activities & & 1.25 & 0.09 & 0.63 & 0.82 \\
\hline 6 & Sexual relationship & & 0.59 & 0.87 & 0.82 & 0.5 \\
\hline 7 & Children and parenting & & 0.7 & 0.71 & 0.48 & 0.97 \\
\hline 8 & Family and friends & & 0.56 & 0.45 & 0.8 & 0.54 \\
\hline 9 & Religious orientation & & 0.98 & 0.28 & 0.59 & 0.88 \\
\hline 10 & Total marital satisfaction & & 0.97 & 0.3 & 0.91 & 0.37 \\
\hline 11 & Personality issues & \multirow{10}{*}{ 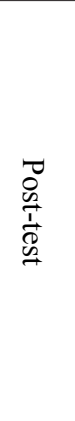 } & 0.74 & 0.53 & 0.91 & 0.37 \\
\hline 12 & Communication & & 0.6 & 0.8 & 1.11 & 0.17 \\
\hline 13 & Conflict resolution & & 0.91 & 0.29 & 1.08 & 0.19 \\
\hline 14 & Financial management & & 0.91 & 0.4 & 0.7 & 0.71 \\
\hline 15 & Leisure activities & & 1.1 & 0.09 & 0.72 & 0.68 \\
\hline 16 & Sexual relationship & & 0.83 & 0.87 & 0.84 & 0.48 \\
\hline 17 & Children and parenting & & 1.03 & 0.71 & 1.2 & 0.11 \\
\hline 18 & Family and friends & & 0.73 & 0.45 & 1.34 & 0.06 \\
\hline 19 & Religious orientation & & 0.93 & 0.35 & 1.12 & 0.16 \\
\hline 20 & Total marital satisfaction & & 0.69 & 0.73 & 1.3 & 0.06 \\
\hline
\end{tabular}

As shown in Table 1, in the pretest and posttest, the pre-assumption of normal distribution of variables were observed for both experimental and control groups in terms of marital satisfaction and its dimensions $(p>0.05)$. In Table 2, results of studying the pre-assumption of equality of variances in the posttest are presented.

Table 2 Results of levene's test

\begin{tabular}{|c|c|c|c|c|c|c|}
\hline \multirow{2}{*}{ Row } & \multirow{2}{*}{$\begin{array}{l}\text { Marital satisfaction } \\
\text { dimensions }\end{array}$} & \multirow{2}{*}{ Test } & \multicolumn{4}{|c|}{ Levene's test } \\
\hline & & & $\mathrm{F}$ & df1 & df2 & $\mathrm{p}$ \\
\hline 1 & Personality issues & \multirow{10}{*}{ 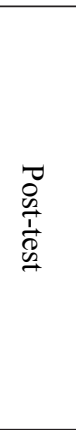 } & 0.14 & 1 & 38 & 0.71 \\
\hline 2 & Communication & & 2.37 & 1 & 38 & 0.13 \\
\hline 3 & Conflict resolution & & 0.32 & 1 & 38 & 0.58 \\
\hline 4 & Financial management & & 0.42 & 1 & 38 & 0.52 \\
\hline 5 & Leisure activities & & 1.49 & 1 & 38 & 0.23 \\
\hline 6 & Sexual relationship & & 2.23 & 1 & 38 & 0.14 \\
\hline 7 & Children and parenting & & 3.43 & 1 & 38 & 0.07 \\
\hline 8 & Family and friends & & 0.01 & 1 & 38 & 0.91 \\
\hline 9 & Religious orientation & & 3.35 & 1 & 38 & 0.07 \\
\hline 10 & Total marital satisfaction & & 0.64 & 1 & 38 & 0.43 \\
\hline
\end{tabular}


As shown in Table 2, the pre-assumption of equality of error variances was observed in the posttest for marital satisfaction and its dimensions $(p>0.05)$. Mean and standard deviation of marital satisfaction and its dimensions in the experimental and control groups in the pretest and posttest are given in Table 3.

Table 3 Mean and standard deviation of marital satisfaction and its dimensions in both research groups in the pretest

\begin{tabular}{clcccccccc}
\hline & & \multicolumn{4}{c}{ Pretest } & \multicolumn{4}{c}{ Posttest } \\
\cline { 2 - 10 } Row & $\begin{array}{l}\text { Marital Satisfaction } \\
\text { Dimensions }\end{array}$ & $\begin{array}{c}\text { Experimental } \\
\text { group }\end{array}$ & \multicolumn{2}{c}{ Control group } & \multicolumn{2}{c}{$\begin{array}{c}\text { Experimental } \\
\text { group }\end{array}$} & \multicolumn{2}{c}{ Control group } \\
\cline { 2 - 10 } & & M & SD & M & SD & M & SD & M & SD \\
\hline 1 & Personality issues & 2.23 & 0.38 & 2.6 & 0.32 & 4.35 & 0.3 & 3.17 & 0.24 \\
2 & Communication & 2.05 & 0.42 & 2.52 & 0.31 & 4.34 & 0.36 & 3.35 & 0.49 \\
3 & Conflict resolution & 2.34 & 0.44 & 2.53 & 0.45 & 4.56 & 0.29 & 3.08 & 0.29 \\
4 & Financial management & 2.34 & 0.48 & 2.55 & 0.4 & 4.57 & 0.27 & 3.12 & 0.33 \\
5 & Leisure activities & 2.67 & 0.35 & 2.92 & 0.34 & 4.35 & 0.46 & 2.85 & 0.33 \\
6 & Sexual relationship & 2.43 & 0.53 & 2.78 & 0.46 & 4.64 & 0.25 & 2.68 & 0.36 \\
7 & Children and parenting & 2.2 & 0.97 & 2.74 & 0.56 & 4.65 & 0.19 & 3.25 & 0.39 \\
8 & Family and friends & 2.41 & 0.49 & 2.68 & 0.6 & 4.59 & 0.29 & 3.35 & 0.4 \\
9 & Religious orientation & 2.38 & 0.39 & 2.58 & 0.43 & 4.53 & 0.25 & 3.2 & 0.45 \\
10 & Total marital satisfaction & 2.34 & 0.34 & 2.66 & 0.27 & 4.51 & 0.15 & 3.12 & 0.23 \\
\hline
\end{tabular}

As given in Table 3, mean of all dimensions of marital satisfaction in the posttest (general marital satisfaction, personality issues, marital relations, conflict resolution, financial management, leisure time, sexual relations, children and parenting, relatives and friends, and religious orientation) in the experimental group was higher than that in the control group. To study the research hypothesis, ANCONA was used and its results are given in Table 4.

Table 4 Results of ANCONA on marital satisfaction and its dimensions in the posttest with the control of the pretest

\begin{tabular}{|c|c|c|c|c|c|c|c|c|}
\hline Row & $\begin{array}{l}\text { Marital satisfaction } \\
\text { dimensions }\end{array}$ & SS & df & MS & $\mathrm{F}$ & $\mathrm{p}$ & $\begin{array}{l}\text { Partial Eta } \\
\text { square }\end{array}$ & $\begin{array}{l}\text { Power } \\
\text { of test }\end{array}$ \\
\hline 1 & Personality issues & 11.16 & 1 & 11.16 & 293.69 & 0.001 & 0.91 & 1 \\
\hline 2 & Communication & 7.81 & 1 & 7.81 & 117.99 & 0.001 & 0.8 & 1 \\
\hline 3 & Conflict resolution & 5.83 & 1 & 5.83 & 39.79 & 0.001 & 0.58 & 1 \\
\hline 4 & Financial management & 14.1 & 1 & 14.1 & 155.69 & 0.001 & 0.84 & 1 \\
\hline 5 & Leisure activities & 11.66 & 1 & 11.66 & 112.22 & 0.001 & 0.79 & 1 \\
\hline 6 & Sexual relationship & 10.88 & 1 & 10.88 & 65.17 & 0.001 & 0.69 & 1 \\
\hline 7 & Children and parenting & 22.84 & 1 & 22.84 & 220 & 0.001 & 0.88 & 1 \\
\hline 8 & Family and friends & 10.82 & 1 & 10.82 & 126.28 & 0.001 & 0.81 & 1 \\
\hline 9 & Religious orientation & 10.1 & 1 & 10.1 & 76.37 & 0.001 & 0.72 & 1 \\
\hline 10 & Total marital satisfaction & 9.92 & 1 & 9.92 & 68.02 & 0.001 & 0.7 & 1 \\
\hline
\end{tabular}

Results of Table 4 regarding the investigation of the research hypothesis using ANCONA showed that this therapy (brief SRCT) had a significant effect on all the subscales (general marital satisfaction, personality issues, marital relations, conflict resolution, financial management, leisure time, sexual relations, children and parenting, relatives and friends, and religious orientation). Significance coefficient for all dimensions of marital satisfaction was zero. Eta value was 0.91 for marital satisfaction (i.e. $91 \%$ of the differences between two groups resulted from the application of the therapy), 0.8 in personality issues, 0.58 in marital relations, 0.84 in conflict resolution, 0.79 in financial management, 0.69 in leisure time, 0.88 in sexual relations, 0.81 in children and parenting, 0.72 in relation with relatives, and 0.7 in religious orientation. Statistical power of all the cases was 1, indicating that the first type error did not occur. The results presented in Table 4 demonstrate that the research hypothesis that brief SRCT is effective in all subscales (general marital satisfaction, 
personality issues, marital relations, conflict resolution, financial management, leisure time, sexual relations, children and parenting, relatives and friends, and religious orientation) among incompatible couples was completely confirmed.

\section{Discussion}

The present study aimed to determine the effect of brief SRCT on increased marital satisfaction (general marital satisfaction, personality issues, marital relations, conflict resolution, financial management, leisure time, sexual relations, children and parenting, relatives and friends, and religious orientation) among incompatible couples. The results showed that training brief SRCT was effective in the increase of components of marital satisfaction. Findings of this research were in line with those by Janbaz Freidooni et al. [15], Halford et al. [7], Chaiker [8], Halford et al. [2], Hawkin et al. [4], Finkel et al. [12], Bak and Nef [13], and Lavner and Bradbury [14]. The mentioned studies have all indicated that self regulation in relations can be an effective factor in marital satisfaction or satisfaction with relations among couples. The mechanisms through which self regulation can improve relations among couples are extraordinarily important for understanding the importance of this type of training.

Training self-regulation is seriously formulated with a focus on the methods of communication problems and effort for changing behavioral, cognitive, and emotional patterns which are linked to communication problems. In fact, the emphasis of training self-regulation is on increasing high-level skills such as selfassessment, self-oriented targeting, and selfchange, and evaluating changes. When these skills are acquired, the ability of couples for changing their compatible processes increases $[2,7]$. Furthermore, there is evidence that dissatisfied and distressed couples seriously lack communication and self-regulation skills in their relations. In other words, most of the couples jeopardize their future and continuing their relations by focusing on negative states and emotions [4,12-14]. As represented by the research evidence [15], one of the reasons for such limitations is lack of self-regulation skills. From this viewpoint, it is completely natural that training self-regulation skills would increase marital satisfaction because when the couples are trained to focus on the regulation of positive and constructive relations instead of focusing on their negative relations and emotions, they will undoubtedly provide an opportunity for increasing marital satisfaction. In other words, when couples try to promote and improve their relations by promoting self regulation communication skills, the final result will be increased marital satisfaction. People get married to fulfill their goals and mental and social needs, one of which is the need for union and belonging. If there is no threatening factor for fulfilling such a need, the factor for fulfilling the needs will generate the internal feelings of satisfaction and thus provide the opportunity for increasing marital satisfaction. In this regard, self-regulation skills, before causing marital satisfaction, induce self-satisfaction, life-satisfaction, and finally marital satisfaction and compatibility. Hence, the first mechanism involved in the strengthening power of self-regulation skills for marital satisfaction is the increase and promotion of self-satisfaction and lifesatisfaction, leading to marital satisfaction.

Strengthening power of self-regulation skills for marital satisfaction is also related to the role of these skills in the ability to control anger and negative emotional behaviors along with the control and management of mental stress in marital relations. Some researchers like Finkel et al. [12], Bak and Naf [13], and Lovener and Bradbury [14] have mentioned that couples with problems in their relations have mostly focused on negative emotions and failed in stress selfregulation. Furthermore, some studies [1,7] have demonstrated that many couples who are distressed in communication with each other mostly express lack of proper communication and inability to resolve their conflicts as their main problems. When couples have problems in the expressing their feelings, they easily 
experience conflict and anger and make their relations hostile [4,12-14]. The couples with distressful and defective relations do not listen to each other and avoid discussions about their problems (a form of passive aggressiveness) [11]. Training self-regulation of relations and interactions contains skills and techniques which seriously cope with the communication conflicts and struggles and weaken them. In fact, generating a sincere relation at the time of anger or hopelessness is naturally challenging. At these times, mind of each one of the couples is filled with negative feelings; thus, conflict and struggle will occur even though one or both of them make efforts. To cope with such conditions (release of negative feelings), one of the best methods is attempts for establishing indirect communication (such as writing notes or letters). To train self-regulation skills, such procedures play a role in controlling anger. For example, in the third and fourth sessions of brief SRCT, redefinition of elements of a positive relation between the couples and identification of critical points of the marital relations to attributional change along with the couples' expectations from each other, feedback, and sum of strengths and weaknesses of relations are considered. Redefinition of elements causes the couples to become aware of their loneliness and concerns and general elements of communication including verbal skills and comprehension skills are worked on. The couples also consider their expectations from each other about different issues in their married life and might disrupt their relation and identify and study strengths and weaknesses of their relations. For instance, in training self-regulation, strengths of the relation such as duration of married life, occasional supports during the married life, exchange of kindness and love beside disputes among the couples, unsound relations, and unsatisfactory sexual relations are considered [1]. When the couples gain such ability through practice to resolve their disputes, marital satisfaction level will undoubtedly increase by correcting form and type of hostile relations.

The effect of training self-regulation to the couples is also related to change in self- confidence and focus of control in marital relations due to the feedback received from each other in the process of changing and correcting inefficient behavioral patterns. The fourth session is based on self-regulation in feedback. There is enough evidence that the couples who have problems with each other cannot give proper feedback [11]. Feedback has some functions in psychological terms. The first and most important function is that it provides the person with an image of him/ her. This image strengthens self-confidence if it is positive and weakness self-efficiency if it is negative. It seems that the couples with problems consider their spouse as an inefficient person who lacks self-confidence due to negative feedbacks to each other. Such a position will increase tension and conflict in the case of acceptance, because an incapable and inefficient person cannot be expected to have seriously positive and constructive behaviors. Therefore, by making a space full of inefficiency and inability, such couples unintentionally intensify problems, leading to seeking assistance, divorce, and separation. Self-regulation training helps couples leave destructive cycle of inefficiency-lack of selfconfidence and improve their relations. Such a trend would reasonably increase marital satisfaction.

\section{Conclusion}

Findings of the present research showed that brief self-regulation training for incompatible couples increased their marital satisfaction. Therefore, it can be concluded that brief selfregulation training is an effective method for strengthening marital satisfaction. Based on the findings of this research, self-regulation training is recommended to be included in educational-therapeutic plans of family consultation and therapeutic centers for the couples who present to these centers due to communication problems and marital dissatisfaction. The second recommendation is use of psychological educational-therapeutic methods such as couple therapy based on self-regulation for changing and correcting 
inefficient and problematic relations among the couples, who cause high stress in their relations with each other but do not go to family consultation centers for different reasons. Such training can be implemented through CDs, web-based or media-based training programs (such as TV programs) for these couples. This recommendation has the advantage that the couples who are not able to learn these skills through self-study are highly encouraged to start solving process of their communication problem by going to therapeutic and training centers. Besides all the above-mentioned discussions and recommendations, it is necessary for the readers and researchers to pay attention to some cases such as self-representation of the couples for communication and marital problems at the time of participation in the research, selection of the initial sample for assignment to experimental and control groups using convenience method, and the criterion variable of this research to marital satisfaction and its dimensions as the limitations of this research.

\section{Acknowledgements}

We hereby appreciate all the couples who helped us conduct this research.

\section{Contribution}

Study design: MG, MN

Data collection and analysis: $\mathrm{MG}, \mathrm{MN}$

Manuscript preparation: MG, MRM

\section{Conflicts of Interest}

"The author declares that they have no competing interests."

\section{Funding}

The author (s) received no financial support for the research, authorship and/or publication of this article.

\section{References}

1- Halford WK. Brief couple therapy. New York: Guilford press; 2001.

2- Halford WK, Lizzio A, Wilson KL, Occhipinti S. Couple relationship self-regulation and satisfaction in the first 4 years of marriage. J Fam Psychol2007; 21(2): 185-94.

3- Duncan S, Holman T, Yang C. Factors associated with involvement in marriage preparation programs. Fam Relat2007; 56: 270-8.

4- Hawkins AJ, Blanchard VL, Baldwin SA, Fawcett EB. Does marriage and relationship education work? A metaanalytic study. J Consult Clin Psychol2008; 76(5): 72334.

5- Papp L, Cummings E, Goeke-Morey M. For richer, for poorer: Money as a topic of marital conflict in the home. Fam Relat2009; 58: 91-103.

6- Halford WK, Osgarby SM, Kelley A. Brief behavioral couples's therapy: A preliminary evaluation. Behav Cogn Psychother 1996; 24: 263-73.

7- Halford WK, Wilson K, Lizzio A, Moore E. Does working at a - relationship work relationship self regulation and relationship outcomes. Australian Research Council Grant entitleg Chapter Eighteen. [On-Line]. Available at URL: http:// griffithuni.net/ school/psy. Accessed 22 June 2013.

8. Chaiker JH. Self - regulation and wisdom in relationship satisfaction- Unpublished [dissertation] in Applied Psychology. Brisbane: Griffith University 2003. pp: 142.

9- Wilson K, Halford K. Processes of change in selfdirected couple relationship education. Fam Relat2008; 57: 625-35.

10- Halford WK, Markman H, Kline G, Stanley S. Best practice in couple relationship education. J Marital Fam Ther2003; 29(3): 385-406.

11- Halford WK. The future of couple relationship education: Suggestions on how it can make a difference. Fam Relat2004; 53: 559-66.

12- Finkel EJ, De Wall C, Slotter EB, Oaten M, Foshee VA. Self-regulatory failure and intimate partner violence perpetration. J Pers Soc Psychol2009; 97: 483-99.

13. Buck AA, Neff LA. Stress spillover in early marriage: The role of self-regulatory depletion. J Fam Psychol2012; 26(5): 698-708.

14- Lavner JA, Bradbury TN. Why do even satisfied newlyweds eventually go on to divorce? J Fam Psychol2012; 26(1): 1-10.

15- Janbaz Feridonie K, Tbrizie M, Navabinezad S. The impact self regulation brief couple therapy increase couple's satisfaction in the clients of Babolsar Farhangian clinic. Journal of Family Research2008; 4(3): 213-29.

16- Sarmad Z, Bazargan A, Hejazi E. Research methods in behavioral science. 1th edition, Tehran: Rasa press; 1997.

17- Soleymanian AI. The study effect of irrational thoughts on the basis of cognitive approach on marital satisfaction. [Thesis]. Tehran: Teacher Education University; 1993.

18-Fahimi R. The study of the relationship between parents marital satisfaction with their adolescence depression. [Thesis]. Tehran: Teacher Education University; 2001. 